\title{
Body composition, dietary salt and sugar intake as determinants of breast cancer: a case-control study
}

\author{
J. L. D. Bernardi ${ }^{1}$, J. C. N. Gomes ${ }^{2}$, K. C. P. McLellan ${ }^{1}$, V. A. L. Merhi ${ }^{1}$ and M. C. de Souza ${ }^{3}$ \\ ${ }^{1}$ Pontificia Catholic University, School of Nutrition, Campinas, SP/Brazil, ${ }^{2}$ Pontificia Catholic University, School of \\ Medicine, Campinas, SP/Brazil and ${ }^{3}$ Nutrition Course, Faculty Heath Sciences Methodist University of Piracicaba, \\ SP/Brazil
}

Breast cancer is the second most prevalent type of cancer worldwide ${ }^{(1,2)}$. Treatment involves multiple aspects such as physical, psychological, social, cultural, spiritual and economic. A holistic view of the patient and a multidisciplinary approach are mandatory. A healthy lifestyle plays an important role in the prevention of this type of cancer.

The aim of this study was to identify the dietary and body composition determinants of breast cancer among menopausal and healthy patients A total of ninety three menopausal women were included in the study and were divided in two groups: without cancer (G1; $n$ 61) and with breast cancer $(\mathrm{G} 2 ; n$ 32).All individuals in both groups had their clinical, metabolic and dietetic profiles examined. Student's $t$-test and Mann-Whitney test were used in the statistical analysis. The CI was set at $95 \%$ and significance level at $5 \%(P<0.05)$. Patients in G2 were older than G1 (mean 59 (SD10.0) years and 57(SD7.4) years, respectively). BMI was similar between groups yet intra abdominal fat $(P=0.02)$ and arm fat $(P=0.04)$ were higher among individuals of $\mathrm{G} 2$, and muscle mass was higher among $\mathrm{G} 1$. Dietary intake differed between groups as G1 had higher intake of protein and cholesterol $(P=0.01$ and $P=0.03$, respectively), although energy intake was similar. G2 had higher intake of salt $(P=0.04)$ and sugar $(P=0.01)$ compared with $\mathrm{G} 1$.

Table 1. Characteristics of individuals in both groups

\begin{tabular}{|c|c|c|c|c|c|}
\hline & \multicolumn{2}{|c|}{ G1 } & \multicolumn{2}{|c|}{$\mathrm{G} 2$} & \multirow[b]{2}{*}{$P$-value } \\
\hline & Average & SD & Average & SD & \\
\hline Age, years & 57 & 7.4 & 59 & 10.0 & 0.8243 \\
\hline BMI & 28 & 6.8 & 28 & 5.2 & 0.9678 \\
\hline $\mathrm{WC}, \mathrm{cm}$ & 99 & 12.0 & 98 & 13.0 & 0.6872 \\
\hline Arm fat, $\mathrm{cm}^{2}$ & 38 & 19.0 & 44 & 17.0 & 0.0454 \\
\hline Midarm circumference, $\mathrm{cm}^{2}$ & 52 & 22.0 & 39 & 17.0 & 0.0027 \\
\hline Protein, $\mathrm{g}$ & 82 & 39.0 & 63 & 32.0 & 0.0150 \\
\hline Cholesterol, mg & 224 & 184.0 & 149 & 121.0 & 0.0318 \\
\hline Salt, $\mathrm{kg} / \mathrm{month} /$ per person & 0.81 & 0.71 & 0.98 & 0.45 & 0.0453 \\
\hline Sugar, $\mathrm{kg} / \mathrm{month} /$ per person & 4 & 4.8 & 5.5 & 3.6 & 0.0147 \\
\hline
\end{tabular}

BMI, body mass index; WC, waist circumference; G1, women without cancer; G2, women with breast cancer; SD, standard deviation.

Menopausal women with breast cancer presented different dietary pattern and nutritional status than healthy women, especially body fat and intake of salt and sugar.

1. INCA. Instituto Nacional do Câncer. Ministério da Saúde 2007/Estimativas 2006. Disponível na internet http:www.inca.gov.br

2. Parkin DM, Bray FI \& Devesa SS (2001) Cancer burden in the year 2000. The global picture. Eur J Câncer 37, 54-66. 